\title{
El talante intelectual de Alberto Hurtado ${ }^{1}$
}

\author{
Juan Ochagavía \\ ANTIGUO DECANO DE LA FACULTAD DE TEOLOGÍA \\ PONTIFICIA UNIVERSIDAD CATÓLICA DE CHILE
}

Sin duda Alberto Hurtado fue muy activo, gran amigo de los jóvenes y de los pobres. Recoger niños vagos y ofrecerles una educación en el Hogar de Cristo es un gesto divino de solidaridad. Pero esto no nos puede hacer desconocer u olvidar su dimensión intelectual y de hombre de estudio. Hacerlo, sería fallarle en algo esencial, desvirtuar su imagen y pasar por alto un constitutivo de su misma santidad.

Me propongo ahora ofrecerles un breve cuadro del trabajador intelectual, riguroso e incansable, que él fue. Esto nos ayudará a conocer mejor las características de su inteligencia y de su santidad, dos dimensiones que él se esforzó por integrarlas, sin jamás oponerlas, como desgraciadamente le gusta hacer a algunos. Aparecerá también la fuerte presencia de "lo universitario" en toda su vida, lo que es un punto importante para esta Universidad Católica, su alma mater, que trata de que, al igual que su patrono Alberto, sea Cristo quien siga inspirando todo el quehacer y la vida de sus miembros.

\section{Un TALENTO NORMAL QUE SE AGIGANTA}

De joven el jesuita Alberto alude varias veces a su "falta de talento" y a su falta de "aplicación al estudio". En reacción a esto, se propone "estudiar mucho" y "seguir con mucha docilidad las indicaciones de los profesores”. Esto resulta extraño, porque el que así habla es un joven abogado que terminó sus estudios de Leyes y Ciencias Políticas "con distinción unánime”. ¿Qué podemos pensar de su talento?

Conferencia dictada el 18 agosto del 2016 con motivo de la celebración de uno de los patronos de la Facultad, San Alberto Hurtado. 
En el colegio de San Ignacio había sido un buen alumno, de "excelencia", mas no de los primeros. Pero este colegial, que no se preocupaba de ser el primero de su clase, se desquitaba leyendo en vacaciones. De 16 años da cuenta a su amigo Manuel Larraín de una impresionante lista de lecturas y lo invita a que "en lugar de llenarte la cabeza de novelas, leyeras algunos libros serios, que verías que te harían bien”.

\section{COMO UNIVERSITARIO}

Ya alumno de derecho de la Católica, le dice a su amigo Manuel “...eso de seguir las leyes solas yo lo encuentro ridículo, fui a la Universidad y vi que no había más de tres horas de clase diarias, lo cual es una miseria”. Para aprovechar su tiempo Alberto toma clases de economía y un curso de dos meses y medio de contabilidad, y le pide a Manuel que lo acompañe en esto $(63,8)$.

En Leyes fue un alumno destacado, el tercero de su clase $(31,39)$. En los Círculos de Estudio de la Congregación Mariana de universitarios estudiaba los documentos de la Iglesia, especialmente los relacionados con la doctrina social, y casi cada mes escribía artículos sobre estos temas en el boletín Efemérides Marianas.

En el colegio, Alberto había aprendido francés, siendo capaz de leerlo y hablarlo con facilidad. El inglés lo llegó a leer bien en la Universidad, lo utilizó en su tesis de licencia, y más tarde, en Irlanda, perfeccionó el lenguaje hablado. El italiano lo leía con soltura. En la Universidad, junto con su amigo Álvaro Lavín, estudió latín para ir así adelantando en los estudios que le exigirían en la Compañía de Jesús, y logró un buen dominio del latín hablado y escrito (Pos 31,3). El alemán lo estudió más tarde en el juniorado de Córdoba, Argentina.

Las dos Memorias de Derecho, para recibirse de bachiller y licenciado en Leyes y Ciencias políticas, muestran su sensibilidad e inclinación a los problemas sociales de su tiempo: "Reglamentación del trabajo de los niños" (46 págs.) y "El trabajo a domicilio" (55 págs.). Revelan una característica de su inteligencia, capaz de sentir empatía y moverse por el prójimo, en especial por los niños y jóvenes, lo que se continuará manifestando en su labor pedagógica en colegios y en el Hogar de Cristo. 
Muestran asimismo algunas características intelectuales notables que crecerán a lo largo de su vida: pensamiento metódico, ordenado, fundado en hechos recogidos de la realidad (encuestas, visitas a Curanilahue), empleo de la legislación comparada (para lo que le servía su manejo de varias lenguas), honestidad para dar cuenta de los límites de su investigación, búsqueda de soluciones sensatas y realistas, no escribe párrafos bonitos sino que propone soluciones.

Títulos académicos. Alberto ingresa de 22 años a la Compañía de Jesús y se ordena sacerdote 10 años después. Pero prosigue sus estudios hasta fines de 1935, o sea un total de 12 años. El 15 de febrero de 1936 llega a Chile con tres licencias (Leyes, Filosofía y Teología) y un doctorado (Pedagogía con mención en Psicología). Empieza una intensa labor como docente y sacerdote, dos realidades que él siempre las vivió unidas. Enseñaba religión en el colegio de San Ignacio y pedagogía en la Universidad Católica, fiel al compromiso que había tomado con su amigo y rector, don Carlos Casanueva.

Impresiona pensar que este hombre que en Chile solo trabajó 16 años como sacerdote, haya vivido 30 años estudiando. Y que lo hiciera con entusiasmo, dedicación y logros notables. Es algo que conviene no olvidar.

\section{HUMANIDADES CLÁSICAS}

Después del Noviciado Alberto estudió humanidades clásicas en Córdoba, Argentina, cosa que lo marcó muy hondo. Allí alternaban el arte, la literatura, la historia y las lenguas. Siguió perfeccionando su latín y estudió griego. En unas conferencias al clero, años más tarde, les dirá que antes de hablar sobre los conocimientos teológicos, se ha de poner una sólida base en los profanos. Les dice: "hemos de ser sensibles al mundo de lo bello en el arte, en la cultura, en la literatura, en la música y hasta en la cultura corporal".

Con profundidad les añade: "El mal gusto tendrá consecuencias fatales... La falta de gusto formado es peligrosa para un sacerdote. Si este no posee ningún sentido de la armonía, de la proporción, será también inseguro en el juicio de los hombres. Allí no habrá armonía entre lo verdadero y lo bello... A lo bello le corresponde un puesto tan esencial como a lo bueno y a lo verdadero". 


\section{La TEOLOGÍA DE LovAinA}

Circunstancias internas de España hicieron que, después de algunos meses de iniciada la teología, Alberto la continuase en Lovaina, donde estuvo desde 1931 a 1935 . Lovaina era un centro intelectual de mucho prestigio. Alberto se zambulló con entusiasmo en ese medio, dejando fama de muy buen estudiante. La teología de Lovaina lo marcó muy hondo y agrandó su mente y corazón a esos nuevos horizontes de Iglesia y de mundo que más tarde cristalizaron en el Concilio Vaticano II.

Creía profundamente que la teología es "el gran estudio sacerdotal”, lo que "es mucho más que pasar exámenes sobre materias teológicas". Para él "no hay estudio más apasionante si se hace con seriedad". La concebía como "...un trato profundo y personal con la Palabra de Dios; un beber dicha palabra en la Escritura y en la Tradición”, “...debe abarcar la vida toda a la luz de la revelación...”, “...es la ciencia de Dios y la suma más alta del saber humano...”.

Esta concepción tan rica de la teología fue creciendo en Alberto hasta el fin de su vida. Podemos decir que nunca dejó de hacer teología. A medida que conoció nuevas personas, nuevos desafíos, nuevos autores, y se jugó por llenarlos del Espíritu de Cristo, se hizo más teólogo, más lleno de la Palabra de Dios.

\section{El DOCTORADO EN PEDAGOGÍA}

El interés de AH por la pedagogía le viene desde colegial en San Ignacio. Su director espiritual, el P. Vives, percibió esto y lo orientó no solo a lo social sino también a lo pedagógico. Por esto se especializó en este campo, haciendo su tesis sobre Dewey. Su inteligencia y gran capacidad de trabajo le permitieron sacar simultáneamente la licencia en teología y el doctorado en pedagogía con mención en sicología.

¿Qué mueve a este jesuita chileno, criado en un valle de Casablanca, a escribir en francés sobre un pedagogo y filósofo norteamericano? Lo mueve algo muy ignaciano: el MAGIS, el mayor servicio de Dios. De hecho, Dewey era el principal exponente de la "Educación Nueva", la figura más representativa del pensamiento pedagógico moderno, de enorme influjo no solo en los Estados Unidos, sino en las reformas educacionales de Rusia, China, Japón, Alemania, India, Bélgica, Suiza y América Latina. 
En aquellos años muchos católicos rechazaban la posibilidad de aplicar en pedagogía las ideas de Dewey, por considerarlas inseparablemente ligadas a fundamentos filosóficos inaceptables. AH se propone, como lo dice en el título, dar un juicio doctrinal sobre la obra pedagógica de su autor. Para ello emplea un enfoque genético evolutivo. En vez de concentrarse en la filosofía del último Dewey, señala cómo a lo largo de 50 años su pensamiento filosófico evolucionó muchísimo. Y lo muestra dialogando, a través de Dewey, con el intuicionismo escocés, con Hegel, con Williams James y los instrumentalistas norteamericanos.

Un Alberto en diálogo con el pensamiento de grandes filósofos no es la imagen pública que de él tenemos en Chile. Para la mayoría su imagen es cuando él recoge, niños del Mapocho. Y sin embargo, la imagen del académico, que dialoga con los pensadores de su tiempo, es también él. Y no lo hacía solo por cumplir con los requerimientos de una tesis doctoral. Esto lo demuestra el hecho de que años más tarde, inmerso en Chile en un intenso quehacer, estudiará a Maritain, Mounier, Jean-Paul Sartre y otros filósofos, y escribirá sobre ellos. No, el diálogo con la cultura, la filosofía y la religión, con las corrientes vivas de la sociedad, es un constitutivo esencial de la personalidad, de la obra y de la santidad de Alberto Hurtado.

Frente a los nuevos movimientos de renovación pedagógica, Alberto se mostró profundamente interesado y a la vez muy libre para criticarlos: "no todo es oro puro". Pero rescata de Dewey sus enormes aportes a la educación: el amor y el respeto al niño, al adolescente y al joven. Igualmente, la invitación a los padres de familia y educadores a ganarse la confianza de los niños. Insta a los profesores a que sus alumnos los vean como amigos, porque no basta instruir, hay que educar, "y lo que valoriza la vida no es la instrucción, sino la educación. Porque después de todo, la instrucción da algo al hombre, pero no lo hace mejor y lo que importa en la vida no es tener algo, sino ser algo". Para educar hemos de inspirar y entusiasmar.

Alberto coincide con Dewey en lo fundamental que es el cultivo en los educandos de las virtudes humanas: la urbanidad, la educación, la cortesía, la caballerosidad, el respeto por los demás y por las cosas. No separarlas de las virtudes sobrenaturales porque "en el orden actual no hay virtud que sea puramente humana para el cristiano" (tesis de su profesor Louis Malevez, SJ, de antigua raigambre en Santo Tomás y los 
Padres). Esta idea abre un campo muy amplio y fecundo al quehacer universitario y a su pastoral.

A estos aportes, que se refieren más bien a la educación escolarizada, habría que añadir su inmensa contribución a crear una conciencia social viva y operante, a renovar el interés de la juventud por los valores morales, a sacudir una fe católica individualista y dormida, a la formación de los obreros en las escuelas sindicales, a encontrar los valores educativos del cine. Cada una de estas cosas que acabo de mencionar el P. Hurtado las estudió y escribió sobre ellas

\section{SU AMOR A LOS LIBROS}

Alberto de joven había sido un buen lector. No de "novelitas rosa", como le escribía a su amigo Manuel Larraín, sino de literatura, que le formaba "el gusto", y de otros "libros serios" que lo marcaron en su vida. Bueno, este rasgo de amor a los libros, a leer y escribir libros, lo acompañó toda su vida. Puso en práctica la recomendación de que para entender bien un problema hay que escribir un libro. De hecho, en 16 años escribió 12 libros y numerosos artículos.

Ya próximo a terminar sus estudios en Europa, se preocupó de adquirir los libros que necesitaría para su trabajo. Con ayuda del Ministerio de Relaciones Exteriores de Chile, que le otorgó una cierta representación diplomática, se las ingenió para conseguir que le regalaran una biblioteca especializada, la mayor parte en alemán, en Ciencias de la Educación y Sicología.

En su cuarto del Colegio de San Ignacio tenía un estante con unos doscientos libros para prestar y un cuaderno donde los anotaba.

\section{“Estar AL díA”}

Estar al día es para el Padre Hurtado una obligación central. Tiene que orientar a muchos desde la sala de clase, el púlpito y la dirección espiritual. Además, recibe muchas consultas. No faltan mamás jóvenes que lo consultan sobre la legitimidad del uso de progestágenos para regular la natalidad, y él les tiene una respuesta sabia y bien fundada. Los Obispos lo han nombrado Asesor Nacional de la Acción Católica de Jóvenes y su palabra es escuchada con avidez por miles de jóvenes a lo largo del país y más allá de sus fronteras. La juventud mundial está 
tironeada por el nazismo, el fascismo, el comunismo, el individualismo, la religión del pasarlo bien y la increencia occidental. Su desorientación es muy grande.

Por eso en su ya muy apretada agenda se busca espacios para estudiar y preparar las clases, conferencias y retiros con sus libros favoritos de teología y con revistas de actualidad teológica, pedagógica y social. Revisando sus apuntes para la beatificación me encontré con una clase que nos dio en mi último año de colegio sobre la religión en la Rusia milenaria. Este era el P. Hurtado: en vez de tronar contra el comunismo, nos abría horizontes fascinantes. Recuerdo que su clase la preparó en base a escritos de Berdiaeff y Block.

Para estar al día es incansable en consultar y conversar con personas especialistas en sus materias. Cultiva amistades centradas en "pensar la Iglesia, el mundo y el país”. Entre estos ocupa un primer lugar don Manuel Larraín, obispo inquieto por el acontecer y los signos de los tiempos. Entre sus compañeros jesuitas, conversa mucho con los Padres Pedro Alvarado, Juan María Restrepo y Gustavo Weigel, todos de esta Facultad de Teología. Sus viajes los aprovecha para abrirse a las nuevas ideas fuerza que están empujando a la Iglesia y al mundo. Ama las ideas de Francia, no por esnobismo sino porque Francia era pionera. También bebe con gusto de las realizaciones de los Estados Unidos. Así se mantenía al día.

Es un ejemplo significativo de este afán de informarse de buena fuente y estar al día, el viaje que, a pocos días de tomar el barco de vuelta a Chile, emprende en tren desde Bélgica hasta Feldkirche, en el sur de Alemania, a conversar con el P. Agustín Rösch, provincial jesuita, sobre el nazismo. Rösch, a quien los nazis lo llamaban der Fuchs (el Zorro), tenía la mejor información y redes de contactos sobre el nazismo y hacía de vínculo con la Santa Sede. Ahí pudo saber de primera fuente lo letal de esta ideología. A su llegada a Chile se encontró con círculos católicos con un cierto romanticismo filonazi. Alberto no abrigaba ningún entusiasmo por ello: ya estaba por comenzar la persecución a los judíos y las cámaras de gas.

Para interiorizar y personalizar estos esfuerzos por estar al día se impuso la disciplinada tarea de cada dos años hacer su propio balance de la situación del mundo y de la Iglesia en Chile y en otras naciones y continentes. Su libro ¿Es Chile un país católico? (1941), que conmovió 
a la Iglesia, pertenece a este género literario de estudio y balance de la realidad en un momento dado. También pertenece al mismo género el libro el Humanismo Social (1946). Lo mismo, el informe que presenta al Papa Pío XII sobre la realidad social, económica, política y religiosa de Chile (Sept. 1947) y los informes periódicos que entrega a su Provincial.

Sus juicios y balances del mundo y de la actualidad eclesial, como también de las cosas de la Compañía, tienen seis características muy suyas: $1^{a}$. Son realistas, basados lo más posible en datos de la realidad. Nada de impresiones vagas o subjetivas. Acude con frecuencia a estudios sociológicos. 2a ${ }^{\text {a }}$ Hay en él un a priori favorable a las nuevas situaciones, no es negativo ni condenatorio. Funciona con el "Presupuesto" de los Ejercicios Espirituales de San Ignacio, de que nuestra primera reacción sea tratar de entender bien lo que dice el otro. $3^{a}$. Juicio crítico inteligente y matizado, separando lo que sirve de lo que daña. $4^{a}$. Libertad, franqueza y humildad para exponer su propio parecer. 5a. Mirada siempre esperanzadora. $6^{\mathrm{a}}$. Búsqueda y propuesta de soluciones eficaces. Nada de lamentos desesperanzados ni de descalificaciones ofensivas. Siendo sensible y tímido, era a la vez fuerte, y para él lo propio del cristiano es construir, no lamentarse.

\section{CONCLUSIONES}

Decantemos de lo expuesto algunas de las características de este Santo estudioso y que dio pruebas de poder ser intelectual.

*Había en él un sustrato familiar favorable - mucho por el lado Cruchaga- que lo predisponía al esfuerzo y al estudio.

*Tiene una personalidad generosa y apasionada, que gracias a la formación familiar austera y al apoyo del Colegio, encauza ordenadamente por caminos de superación y servicio a los demás. Alberto siempre decía que una voluntad fuerte se desarrolla ante la presencia de un ideal. Para él este ideal fue Cristo, que lo llamó al sacerdocio en la Compañía de Jesús. Ayudado por la oración, los sacramentos y el acompañamiento espiritual, fue creciendo en unión y entrega a Cristo y en deseos de servirlo. Estoy persuadido de que el amor y el deseo de servir a Cristo, al Cristo completo, al Cristo actuante, doliente y triunfante en los hombres y mujeres de hoy día, ha sido el factor más marcador del desarrollo intelectual del Padre Hurtado. Desconocer esto 
sería alterar los datos de la realidad. No en vano tuvo de profesor en Lovaina al famoso P. Emile Mersch, autor de libros muy doctos sobre el Cristo total.

*En miras el sacerdocio, Alberto se dedicó con ahínco al estudio y aumentó su capacidad de trabajo intelectual, alcanzando niveles de rendimiento muy por encima de lo corriente.

*Estudia con entusiasmo y constancia, rigor y método. Por naturaleza más bien tímido, se esfuerza por mejorar en la expresión oral y escrita. Expone su pensamiento con claridad, convicción y un cierto grado de buen estilo.

* Su inteligencia es realista, no es fantasiosa; busca conocer y se somete a los datos objetivos.

*Posee un gran talento organizativo. No se contenta con el "pensar" sino que pasa a la acción, busca el "hacer". Siente que las ideas - ¡como el dabar bíblico!- son para ponerlas en práctica. Esto es un rasgo muy suyo. Su inteligencia realista lo lleva a hacer la verdad por sus pasos. Es un pedagogo por naturaleza y por formación.

*La necesidad del "hacer" lo mueve a buscar colaboradores y a crear redes: la Acción Católica, las Congregaciones Marianas, la Librería Splendor (hoy las Paulinas de la Alameda sur), el Hogar de Cristo, la ASICH, etc. No siente haber hecho lo bastante antes de realizar todo lo posible. Y cuando no puede más, entonces le encomienda todo a Dios para que Él haga lo que sea su voluntad.

*Pudo haber sido un investigador destacado y un académico brillante, si se hubiese sentido llamado por Dios a dedicarse a esto de por vida. Dio abundantes pruebas de capacidad y constancia de poder serlo. Sin embargo las necesidades de la Iglesia lo llevaron por otros caminos. Pero conocía bien lo que es el nivel y el rigor intelectual y era capaz de trabajar a fondo en temas complejos y difíciles.

*Amante de lo sólido, sin dejarse fascinar por la novedad, es un hombre abierto a lo moderno. Se resiste a la afirmación del Nibil novi sub sole, de que todo lo actual ya haya sido dicho por los autores antiguos.

*En la línea de la inteligencia emocional, posee un gran don de empatía: de adaptarse al otro, entrar en sus problemas, vivir desde dentro su situación interior, hablarle en su idioma. Hemos visto este rasgo en 
396 | Juan Ochagavía

su acercamiento a la filosofía y literatura no católica. Pero donde esto más relucía era en su relación con los demás. Lo que hizo, en frase de su Rector en Lovaina, que todos lo quisieran: "Querido por todos". 